\title{
EM TEMPOS DE MIDIATIZAÇÃO DO ATIVISMO: REPENSANDO CARACTERÍSTICAS DA NARRATIVA JORNALÍSTICA DIGITAL ATRAVÉS DA APROPRIAÇÃO DO MEDIUM PELO MÍDIA NINJA
}

\author{
About times of activism mediatization: rethinking the features of digital \\ journalism narrative through appropriations of medium by mídia ninja
}

En tiempos de mediatización del activismo: repensando las características de la narrativa periodística digital a través de las apropriaciones de medium por mídia ninja

\author{
Maria Clara Aquino Bittencourt \\ Universidade do Vale do Rio dos Sinos \\ Aquino.mariaclara@gmail.com
}

\section{Resumo}

Este artigo parte da premissa de midiatização do ativismo em processos de produção e circulação de conteúdos em contexto de movimentos em rede. Trabalha-se o impacto da midiatização nas práticas jornalísticas digitais para em seguida voltar a atenção para os recursos midiáticos empregados na narrativa construída pelo Mídia Ninja em sua página no Medium, uma ferramenta de publicação de conteúdo adotada pelo coletivo no início de 2014 . O olhar para esta ferramenta permite inferir apontamentos que indicam como a apropriação tecnológica, fundamentada em aspectos sociais e calcada na midiatização do ativismo, é, ao mesmo tempo, capaz de provocar a evolução e promover a continuidade de características da narrativa jornalística digital.

Palavras-chave: Midiatização. Ativismo. Narrativa Jornalística Digital.

\begin{abstract}
This article starts from the premise of mediatization of activism in the process of production and circulation of content in the context of network movements. The impact of mediatization on digital journalism practices is studied to turn our attention to the media resources employed in the narrative constructed by Mídia Ninja on your page in Medium, a tool for publishing content adopted by the collective in early 2014. The look for this tool allows to infer notes that indicate how technological appropriation, based on social and grounded in mediatization of activism respects, is at the same time, able to cause the evolution and promote continuity of features of digital journalism narrative.
\end{abstract}

Key words: Mediatization. Activism. Digital Journalism Narrative. 


\section{Resumen}

Este artículo parte de la premisa de mediatización del activismo en el proceso de producción y circulación de contenidos en el contexto de los movimientos en red. Es estudiado el impacto de la mediatización sobre las prácticas de periodismo digital para luego girar su atención a los recursos de los medios empleados en la narrativa construida por Mídia Ninja en su página en Medium, una herramienta para publicación de contenido aprobado por el colectivo a principios de 2014. La mirada para esta herramienta permite inferir notas que indican cómo la apropiación tecnológica, con base en los aspectos sociales y basadas en la mediatización del activismo, es, al mismo tiempo, capaz de causar la evolución y promover la continuidad de las funciones de la narrativa periodística digital.

Palabras clave: Mediatización. Activismo. Narrativa Periodística Digital.

\section{INTRODUÇÃO}

O campo da comunicação, durante os protestos de 2013, viu o surgimento, e o fortalecimento de já existentes, coletivos midiáticos. Entende-se esses coletivos como grupos que por meio do uso de sites de redes sociais, plataformas e dispositivos móveis de comunicação digital produzem e promovem o espalhamento de conteúdos sobre protestos decorrentes de mobilizações organizadas dentro e fora das redes digitais, e que atuam de forma independente da mídia de massa, podendo ou não participar da organização dos atos e protestos de rua.

A configuração desses coletivos acontece num contexto em que as relações sociais estão cada vez mais midiatizadas, de modo que se pode pensar sobre a midiatização do ativismo a partir de apropriações diversas de tecnologias e ferramentas digitais de comunicação no cotidiano dos movimentos em rede (CASTELLS, 2012) e da cobertura dos mesmos. Essas apropriações partem de atores diversos: cidadãos, identidades coletivas, jornalistas e ativistas, de modo que o impacto das mesmas na narrativa jornalística digital provoca a reflexão aqui proposta.

Já há algum tempo, alguns autores (MIELNICZUCK, 2003; 2005; PALACIOS ET AL., 2002; BERTOCCHI, 2006) consideram a interatividade, a multimidialidade e a hipertextualidade como as principais características do jornalismo digital. Outros, como Mielniczuk (2003; 2005) e Palacios et al. (2002), ainda elencam outras características como personalização/customização de conteúdo, memória, instantaneidade.

Partindo da premissa de que os processos de produção e circulação dos conteúdos desses coletivos são marcados pela midiatização do ativismo, este artigo busca pensar como a narrativa elaborada pelo coletivo midiático Mídia Ninja, no contexto dos movimentos em 
rede, provoca transformações nessas características quando pensadas a partir da perspectiva da narrativa jornalística digital. Inicialmente questiona-se o impacto da midiatização nas práticas jornalísticas digitais para em seguida voltar a atenção para os recursos midiáticos empregados na narrativa construída pelo Mídia Ninja em sua página no Medium ${ }^{1}$, uma ferramenta de publicação de conteúdo adotada pelo coletivo no início de 2014. O foco nessa ferramenta resulta da necessidade de um recorte para a realização da análise, diante da multiplicidade de ferramentas usadas pelo coletivo. Ainda assim, o olhar para esta ferramenta permite inferir apontamentos que indicam como a apropriação tecnológica, fundamentada em aspectos sociais e calcada na midiatização do ativismo, é, ao mesmo tempo, capaz de provocar a evolução e promover a continuidade de características da narrativa jornalística digital.

\section{A MIDIATIZAÇÃO DO ATIVISMO EM CONTEXTO DE REDES}

Fundamentado na ideia de atravessamento entre os campos sociais (BOURDIEU, 1983), o conceito de midiatização vem sendo trabalhado sob diferentes olhares. Parte-se aqui de uma perspectiva histórica, com base em Verón (2014), que entende que "nos últimos dez anos, a internet alterou a condição de acesso ao conhecimento científico mais do que essa condição mudou desde o surto moderno de instituições científicas durante o século XVII". O peso da internet e das tecnologias digitais de comunicação, nesse sentido, interferem na constituição e no desenvolvimento de práticas comunicacionais que, no caso de movimentos em rede, são apropriadas e reconfiguradas na velocidade dos acontecimentos nas ruas. $\mathrm{O}$ campo jornalístico é diretamente impactado por tais apropriações e reconfigurações, já que não se trata mais apenas de organizar ações de rua por meio de dispositivos comunicacionais, mas de reportar ao mundo notícias e informações diversas sobre causas, protestos e manifestações. Desse modo, os estudos sobre narrativa jornalística, nesse caso no ambiente digital, pressupõem um aprofundamento que direcione seu foco para tais transformações. Refletir sobre apropriações jornalísticas no contexto de uma sociedade midiatizada, dessa forma, é voltar a atenção para a apropriação como elemento central na condução de mudanças e na sedimentação de permanências nas relações entre mídia e sociedade.

Fausto Neto (2008) debruça-se sobre o conceito de midiatização a partir da intensificação das tecnologias que são convertidas em meios, conversão esta que vai sendo 
cadenciada por processos de apropriações sociais. Referindo-se ao que chama de "cultura de mídia", o autor destaca práticas sociais, processos interacionais e a própria organização social que se pautam pelas lógicas e operações do campo midiático. Tecnologias vão sendo transformadas em meios de produção, circulação e recepção de discursos e o funcionamento da sociedade acaba atravessado por pressupostos e lógicas que configuram esta cultura da mídia. Diante da premissa de que a expansão da midiatização teria o potencial de colocar produtores e consumidores na mesma realidade de fluxos, quando trabalha-se o conceito no contexto da comunicação de movimentos em rede percebe-se o quanto essa premissa pode ser fazer verdadeira, ainda que com limitações em alguns casos - o que se poderá perceber adiante pela análise realizada.

As práticas comunicacionais de movimentos sociais vem passando por modificações junto com o desenvolvimento das tecnologias digitais de comunicação, e nos últimos anos Castells (2012) ressalta a importância que adquiriram no cotidiano de ativistas e profissionais da imprensa, ao abordar algumas das principais mobilizações em rede que aconteceram no mundo de 2009 a 2012. Antes mesmo deste estudo, ao analisar as relações de poder através do gerenciamento de processos de comunicação, Castells (2009) discorre sobre como essas relações podem ser alteradas por atores sociais que buscam mudança social através da influência sobre a mente pública, ou dos públicos. $\mathrm{O}$ autor trabalha com a hipótese de que a forma mais fundamental de poder se encontra na habilidade de moldar a mente humana que, através da comunicação interage com o ambiente natural e social. Dessa forma, ele explica, a comunicação atua como mediadora da construção das relações de poder em todos os domínios da prática social, inclusive da prática política. Quando se propõe investigar como os movimentos sociais se apropriam das tecnologias comunicacionais e trazem para o seu cotidiano não só de organização (GOHN, 2010), mas de comunicação sobre as lutas, uma diversidade de possibilidades, é a midiatização como conceito que oferece um aporte teórico que remete à reflexão sobre como o ativismo é atravessado por lógicas midiáticas. Há que, no entanto, fazer o tensionamento desse argumento no âmbito das mídias digitais.

Estudando o ativismo político que se utiliza de táticas lúdicas, irreverentes e até mesmo debochadas em contraste à seriedade dos processos políticos, Assis (2006) observa grupos que através dessas táticas atuam com base em estratégias e estéticas que buscam a atenção e a repercussão midiática.

Como o ambiente midiático contemporâneo responde pela função de construção de mitos e a propagação de ideais de todas as escalas e campos 
PROGRAMA DE PÓS-GRADUAÇÃO EM COMUNICAÇÃO DA UNIVERSIDADE FEDERAL DE SANTA MARIA

da experiência social, é necessário ao ativismo assumir a forma-mídia para embrenhar-se pelos meios de comunicação, divulgar suas críticas e propostas de transformação social, e injetar na sociedade a ideia da necessidade de resistência aos processos político-econômicos atuais (ASSIS, 2006, p. 13).

Assis (2006) estuda pequenos coletivos que se utilizam de táticas lúdicas de mídia, mas ainda sim suas considerações sobre a incorporação da mídia nas rotinas comunicacionais desses grupos servem de parâmetro para pensar a midiatização do ativismo no contexto dos movimentos em rede e dos coletivos midiáticos que deixaram marcas na cobertura midiática dos protestos de 2013 no Brasil. Na tentativa de contextualizar o ativismo político contemporâneo, Assis (2006, p. 47) entende que "praticamente todo e qualquer tema contemporâneo que diga respeito aos direitos da sociedade civil [...] aparece de alguma forma dentro do ativismo". Dessa forma, o estreitamento desse campo do ativismo político com as lógicas midiáticas e as apropriações das tecnologias digitais de comunicação desenvolvem o potencial de transformação das práticas comunicacionais através das redes de mobilização social. E a apropriação nesse sentido é fundamental para afastar qualquer entendimento calcado no determinismo tecnológico: "Não é apenas a adoção de tecnologia e de práticas destas, mas sim das próprias lógicas de produção do sistema midiático que determinam esta relação mais intensa" (ASSIS, 2006, p. 51). O autor discorre sobre o tema numa época em que as mídias digitais ainda ensaiavam a representatividade alcançada hoje. Assis (2006, p. 51, 52) destacava então o esforço que pequenos grupos despendiam para fazer com que suas ações ganhassem a atenção da mídia e assim se tornassem notícia, circulando como "acontecimentos representativos de uma época". Tendo o processo de produção, assim como o de circulação, se ampliado para múltiplos atores o esforço pela conquista da visibilidade ainda é o mesmo, porém construído por outras vias, muitas vezes de forma independente da mídia tradicional.

Considerando o atravessamento dos campos como uma das consequências mais significativas da midiatização, Braga (2012a) destaca que esse atravessamento é capaz de gerar situações indeterminadas e experimentações correlatas. As apropriações, nesse sentido, podem determinar o desenrolar de um fato ou acontecimento, ao mesmo tempo em que interferem na produção e na circulação de conteúdo através das redes. Ao experimentar diferentes formas de interação em diferentes modos ou processos sociais, Braga (2012b) entende que essas experimentações se tornam práticas disponíveis para a sociedade, sendo então capazes de modelar processos comunicacionais. $\mathrm{O}$ episódio comunicacional que aciona esses modelos lhes dá forma, sentido, substância e direcionamento, configurando, segundo o 
autor, matrizes que ele chama de dispositivos interacionais, onde acontece a comunicação. Produzidos esses dispositivos de forma tentativa, Braga (2012b) afirma que eles atuam como formas de viabilização da interação. Para ele, as interações modificam e reinventam os dispositivos, sendo assim possível fazer aqui a costura com a ideia de apropriação a partir das interações, que interfere diretamente na constituição e no desenvolvimento dos dispositivos.

Tomando como fulcro da teoria da midiatização a hipótese de que os valores do campo das mídias se sobrepõem aos de outros campos que lhe delegaram funções expressivas, Assis (2006) considera que a midiatização influencia a própria formação e ordenação dos campos. $\mathrm{O}$ valor que as ações midiáticas recebem no cotidiano dos movimentos e mobilizações em rede, ao se pensar aqui no contexto dos protestos de 2013 no Brasil, interfere diretamente na configuração do campo midiático como um todo. Quando Fausto Neto (2010) fundamenta-se na ideia de apropriação como um dos elementos para pensar a circulação como processualidade complexa, é possível fazer o exercício de reflexão sobre o quanto a midiaitização do ativismo interfere na formação e no desenvolvimento da narrativa jornalística digital.

\section{NARRATIVA JORNALÍSTICA DIGITAL}

O entendimento sobre narrativa deriva da noção de atualização como a "capacidade humana de tornar a atualidade mais do que um momento que logo em seguida se perderá da memória" (CARVALHO, 2012, p, 173). Ao considerar o jornalismo como uma forma de narrativa, o autor alerta que é preciso identificar os elementos que assim o constituem e destaca que as notícias relatam o cotidiano, atualizando sobre o que acontece ao redor dos indivíduos. Lembrando como o jornalismo se utiliza de diversas estratégias narrativas para contar uma história, enfatiza que a tarefa de narrar o presente não se detém apenas no aqui e agora, mas apresenta referências ao passado e menções ao futuro. Motta (2012) exalta o retorno da narrativa à cena cultural e aponta que, no ambiente midiático, a narrativa se consolida com novas tecnologias e a aceleração de variados produtos midiáticos da indústria cultural. Na web, ele continua, a narrativa se prolifera por diferentes espaços, como blogs e redes sociais. Sobre os discursos narrativos midiáticos, Motta (2007, p. 144) afirma que são construídos através de "estratégias comunicativas (atitudes organizadoras do discurso) e recorrem a operações e opções (modos) linguísticas e extralinguísticas para realizar certas intenções e objetivos". 
Essa multiplicação constante de espaços, ferramentas e plataformas de comunicação online baseadas na convergência e na multimídia contribuem para a criação de novas formas de narrativa jornalística digital. A integração dessas potencialidades para relatar um acontecimento afeta desde a disposição dos profissionais dentro de uma redação voltada para a produção de conteúdo digital até as formas como esse conteúdo é coletado, trabalhado e colocado em circulação nas redes. Pensar a narrativa jornalística digital é um tema que se desdobra em ângulos diversos de observação. Nesta pesquisa, o foco de análise gira em torno de características do jornalismo digital, com o objetivo de pensar a atual configuração dessas características a partir das práticas empreendidas por um coletivo midiático em contexto de movimentos e mobilizações sociais em rede.

Visando analisar as principais transformações da narrativa jornalística no ciberespaço, Bertocchi (2006) recorre à retórica ciberjornalística e identifica suas bases no que chama de tríplice exigência, formada pelas possibilidades do hipertexto, da multimidialidade e da interatividade. O que Bertocchi (2006) entende como narrativa ciberjornalística é o que se entende aqui como narrativa jornalística digital: "os textos narrativos produzidos por jornalistas e veiculados em espaços digitais noticiosos, mantidos por empresas de informação e comunicação com presença na web”. Olhar para as práticas realizadas por coletivos midiáticos para produzir e fazer circular conteúdo sobre protestos é o recorte definido para tentar identificar transformações nessa narrativa jornalística digital. As características dessa narrativa, elencadas por autores do campo do jornalismo desde os primeiros esforços em jornalismo digital, servem então como categorias de análise que orientam a investigação.

Em um ensaio sobre os dez primeiros anos do jornalismo online, Mielniczuk (2005) aponta decepções e avaliações não muito satisfatórias, mas não deixa de considerar os avanços conquistados. Os primeiros esforços tinham como referência os meios de massa, de modo que uma das principais críticas aos primeiros produtos do jornalismo digital apontavam o pouco ou mau aproveitamento das possibilidades do meio online.

[...]'o jornalismo online está engatinhando', 'ainda há muito a ser descoberto', 'as potencialidades da rede não são aplicadas nos produtos jornalísticos', 'o jornalismo online não passa de uma transposição do impresso (shovelware)', 'ainda não temos soluções satisfatórias para a viabilização comercial de tais produtos', 'não há uma geração formada de profissionais do jornalismo e de leitores para o ambiente web'[...] (MIELNICZUK, 2005, ONLINE).

Os apontamentos indicados pela autora como alguns dos mais frequentes feitos na época, ainda são válidos, em alguns casos, mas há que considerar que o desenvolvimento do 
que se convencionou chamar de web 2.0, e que trouxe sob o termo uma série de ferramentas e possibilidades baseadas na colaboração e na arquitetura de participação, garantiu um novo direcionamento ao jornalismo digital (TRÄSEL E PRIMO, 2006; LINDEMANN, 2006; GILMOR, 2004). A comunicação móvel (SILVA, 2008; CANAVILHAS E SANTANA, 2011), permitida pela expansão de infraestrutura, conexão sem fio e tecnologias móveis, também acarretou mutações fundamentais no desenvolvimento e na reflexão sobre o jornalismo digital, culminando no que hoje no impacto do que se convencionou chamar de mídias sociais (MALINI, 2008).

Ainda no início dos anos 2000, Palacios et al. (2002) empreenderam o esforço de mapear características e tendências de jornais brasileiros, comerciais, diários e gratuitos online e identificar como era feito uso dos recursos oferecidos pelo ambiente digital nas publicações. Apenas jornais online produzidos por empresas de comunicação foram analisados, ficando de fora publicações "amadoras e não profissionais". Os autores partiram da classificação do jornalismo digital, naquele momento, em três fases: a) transposição: em que o conteúdo do veículo impresso era transposto para o ambiente digital; b) metáfora: quando os jornais, ainda presos aos modelos seguidos no impresso, tentam incorporar características oferecidas pela rede; e c) momento atual na época, onde surgiam iniciativas voltadas exclusivamente para web, com características do meio online sendo supostamente aproveitadas, e em que a transmissão de sons e imagens era mais rápida.

Nessa terceira fase, Palacios et al. (2002) trabalhavam com cinco características: interatividade, multimidialidade/convergência, hipertextualidade,personalização/customização de conteúdo e memória, as quais, de acordo com os autores, não eram necessariamente exploradas pelo sites que analisaram, fosse por "razões técnicas, de conveniência, adequação à natureza do produto oferecido ou ainda por questões de aceitação do mercado consumidor". A delimitação dessas características pelos autores e o entendimento que tinham de cada uma indicar algumas causas do pouco aproveitamento das possibilidades do meio online. Mielniczuk (2003) entendia também a instantaneidade como característica da terceira fase, mas mais como uma continuidade do próprio fazer jornalístico do que propriamente uma ruptura. Em 2005, alguns autores, como Schwingel (2005) apontavam a configuração de uma quarta fase do jornalismo digital, caracterizada pelo uso de tecnologias de bancos de dados para apuração, edição e veiculação de informações online.

Sobre a interatividade, os autores destacavam a possível ocorrência de processos multi-interativos quando do acesso a um produto jornalístico, de modo que o usuário 
estabeleceria relações com a máquina, com o conteúdo, através do hipertexto, e com outras pessoas. Para investigar o nível de interatividade nos jornais analisados, os autores basearamse em questões sobre o uso de e-mails, formulários, fóruns, chats e enquetes. Percebe-se, nessa época, a limitação da característica da interatividade às funcionalidades existentes. A interatividade baseava-se na atividade deflagrada por estímulos previamente determinados e os leitores pouco, ou nada, intervinham na construção dos conteúdos. Atualmente, é possível pensar na participação e no compartilhamento como subcategorias da interatividade (AQUINO BITTENCOURT, 2012), na medida em que a ampliação das oportunidades de intervenção reconfigura o processo de circulação das notícias e as mídias sociais conferem ao leitor um papel de replicador de conteúdo, ao mesmo tempo em que em alguns casos pode atuar também como produtor.

Jenkins (2008, p.183) discute a confusão entre as noções de interatividade e participação: "permitir aos consumidores interagir com as mídias sob circunstâncias controladas é uma coisa; permitir que participem na produção e distribuição de bens culturais - seguindo as próprias regras - é totalmente outra". O fato é que proporcionar mecanismos interativos que permitam às audiências a escolha e a personalização do conteúdo trata-se de atitude referente à interatividade, enquanto que observar a reação dos públicos, monitorar o seu comportamento e incorporar os consumidores de informação no processo de produção de conteúdo refere-se à participação. A interatividade não perde força ao longo do tempo, pelo contrário, é hoje incorporada como característica dos meios de comunicação inseridos no contexto digital. E a participação vem seguindo o mesmo caminho, ainda que com alguns obstáculos.

A multimidialidade é apontada por Palacios et al. (2002) como sinônimo de convergência, e entendida como a "convergência dos formatos das mídias tradicionais (imagem, texto e som) na narração do fato jornalístico". Já no início dos anos 2000, Canavilhas (2001) discutia a importância de o jornalismo online criar uma espécie de identidade própria, a partir de uma comparação com meios anteriores à internet.

A televisão, tal como a rádio e o jornal fomentaram no receptor capacidades para a apreensão das suas linguagens. A internet, neste caso o webjornalismo, terá de fazer o mesmo. Mas não basta juntar à notícia um conjunto de novos elementos multimédia, pois esse acto pode apenas criar redundância e até mesmo ruído (CANAVILHAS, 2001]. 
PROGRAMA DE PÓS-GRADUAÇÃO EM COMUNICAÇÃO DA UNIVERSIDADE FEDERAL DE SANTA MARIA

A evolução das ferramentas de publicação, da tecnologia digital e as apropriações feitas pelos usuários das redes cada vez mais demonstram que convergência não é sinônimo de multimidialidade. Em tese de doutorado sobre o conceito de convergência midiática, Aquino Bittencourt (2012) trabalha com aspectos técnicos, sociais e culturais do fenômeno, a partir da crítica sobre o caráter excessivamente técnico com que o conceito é abordado ao longo dos anos. Pensar a multmidialidade como a união de formatos diversos para a constituição da narrativa é diferente da ideia de convergência, que incorpora manifestações sociais e culturais, além de técnicas, na configuração de processos de produção, circulação e consumo de conteúdos midiáticos.

Sobre a customização/personalização do conteúdo, o que se percebe é que a essência dessa ideia permanece, ainda que tenha evoluído em função do desenvolvimento de algoritmos que buscam interpretar - e até mesmo direcionar - as preferências do público leitor. Entendida por Palacios et al. (2002) como a "opção oferecida ao usuário para configurar os produtos jornalísticos de acordo com os seus interesses individuais", hoje a personalização do conteúdo em muitos casos é feita automaticamente, o que acaba tolhendo a liberdade de escolha do leitor e até mesmo limitando a ideia de interatividade com o conteúdo. Em alguns casos trata-se mais de imposição do que de personalização.

A hipertextualidade, entendida pelos autores como a possibilidade de interconexão de textos através de links foi ampliada a outros formatos ao longo dos anos, além de ter sido extendida para práticas colaborativas como é o caso das hashtags. Os autores também não mencionam a possibilidade de escrita colaborativa ofertada pela prática hipertextual, ignorando o papel do leitor na constituição da trama de links. As mídias sociais, nesse sentido, reconfiguram o entendimento sobre o hipertexto na narrativa jornalística na medida em que as atuais ferramentas de publicação e as mídias sociais atrelam o compartilhamento de links como uma de suas principais potencialidades.

Colocando a ausência de limitações de tempo e espaço e a pronta disponibilização da informação ao leitor como as principais vantagens da memória no jornalismo digital, Palacios et al. (2002) ignoram o papel do usuário leitor na formação dessa memória. Através da interatividade (e hoje pela participação e pelo compartilhamento) e da hipertextualidade é possível pensar na constituição da memória no ambiente digital. Para o jornalismo digital de hoje, as atividades dos leitores com o conteúdo e entre si são determinantes na constituição da memória dos fatos na rede, o que demonstra a importância do caráter social e cultural na narrativa jornalística das redes. 
PROGRAMA DE PÓS-GRADUAÇÃO EM COMUNICAÇÃO DA UNIVERSIDADE FEDERAL DE SANTA MARIA

Este breve exercício de aproximação e distanciamento entre as características do jornalismo digital apontadas no início dos anos 2000 e o entendimento das mesmas diante do presente cenário jornalístico online indicam que o pouco uso ou o mau aproveitamento não pode limitar-se a uma análise predominantemente quantitativa, como feita por Palacios et al. (2002). Há que se identificar o papel do leitor diante do espaço que ganha para explorar essas características e contribuir para a circulação dos conteúdos. Investigar o aproveitamento dessas características no caso do Mídia Ninja pode ser útil na tentativa de revelar o impacto dessas narrativas no jornalismo digital.

\section{A NARRATIVA DO MÍDIA NINJA NO MEDIUM}

Os protestos que ganharam força em diversas cidades do Brasil a partir de junho de $2013^{2}$ provocaram o surgimento de coletivos midiáticos, bem como conferiram visibilidade a grupos como este já existentes antes das manifestações, como é o caso do Mídia Ninja. O NINJA - Narrativas Independentes, Jornalismo e Ação nasceu em decorrência de uma série de ações de mídia livre, realizadas desde 2005. Em resposta a questionário ${ }^{3}$, o coletivo se define como "uma rede descentralizada de comunicadores que buscam novas possibilidades de produção e distribuição de informação." O indivíduo que participa cobrindo os protestos nas ruas e enviando conteúdo para a publicação nas ferramentas utilizadas pelo coletivo: Facebook, Twitter, Medium, newsletter, Tumblr e plataformas de streaming é então considerado um ninja.

A quantidade de ferramentas utilizadas pelo Mídia Ninja impede a exposição de uma análise detalhada de todas as características em todos os ambientes dentro de um único artigo, de modo que o corpus trabalhado aqui engloba as publicações feitas no Medium do coletivo (http://medium.com/@midianinja), desde sua criação em 30 de janeiro de 2014 até o dia 30 de outubro do mesmo ano. Diferente de sites de rede social como o Twitter e o Facebook, onde predominam publicações mais curtas, no Medium o conteúdo é mais detalhado, com textos mais longos, o que o aproxima dos blogs em alguns aspectos. Assim, optou-se pela análise desta ferramenta em função dessa possibilidade de publicações mais amplas, que podem explorar diferentes formatos (texto, vídeo, foto e áudio), permitindo observar como o coletivo integra as características do jornalismo digital nesse tipo de espaço. Além disso, a circulação

\footnotetext{
${ }^{2}$ http://pt.wikipedia.org/wiki/Protestos_no_Brasil_em_2013 Acesso: 01/12/2016

${ }^{3}$ https://docs.google.com/forms/d/118i1tMChATl1sTNZ7AI-qJTBgj6Nk78QqvUmMKa8IDw/viewform Acesso: $01 / 12 / 2016$
}

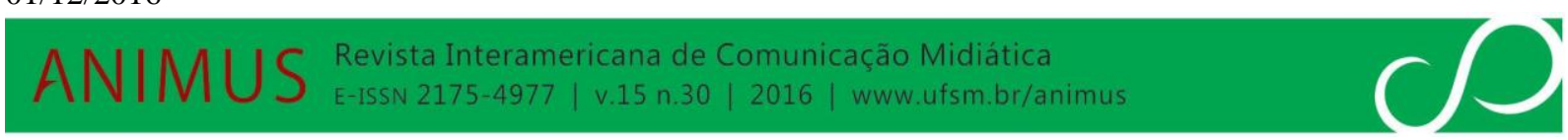


dessas publicações se baseia na recomendação feita pelos usuários, de modo que parte-se da hipótese de que a integração promovida pelo coletivo ao propor a colaboração na construção de suas narrativas aparece na rotina de produção dos conteúdos para essa ferramenta.

A estratégia metodológica adotada tomou como base o modelo híbrido de pesquisa (MACHADO E PALACIOS, 2007) aplicado pelo Grupo de Estudos de Jornalismo Online, da Universidade Federal da Bahia, que trabalha buscando o entrelaçamento entre os fundamentos teóricos e as particularidades de organizações concretas a partir da observação de suas práticas jornalísticas. Inicialmente foi feita uma recuperação do referencial teórico sobre jornalismo digital que elenca suas principais características. A partir desse levantamento foi feita uma análise descritiva e qualitativa da ferramenta Medium, para identificar como as características apontadas pelos autores podem ser e como são trabalhadas na ferramenta pelo Mídia Ninja. O objetivo desse cruzamento entre o referencial teórico e a análise da apropriação feita pelo Mídia Ninja da ferramenta diante de suas possibilidades foi identificar como esse uso pode impactar em transformações na narrativa jornalística à luz da premissa de midiatização do ativismo.

\subsection{Interatividade}

Assim como nos blogs e em sites jornalísticos onde existe a possibilidade de inserção de comentários por parte de quem lê o conteúdo, bem como em sites de redes sociais, o Medium oferece essa possibilidade através da inserção de notas ao longo da publicação.
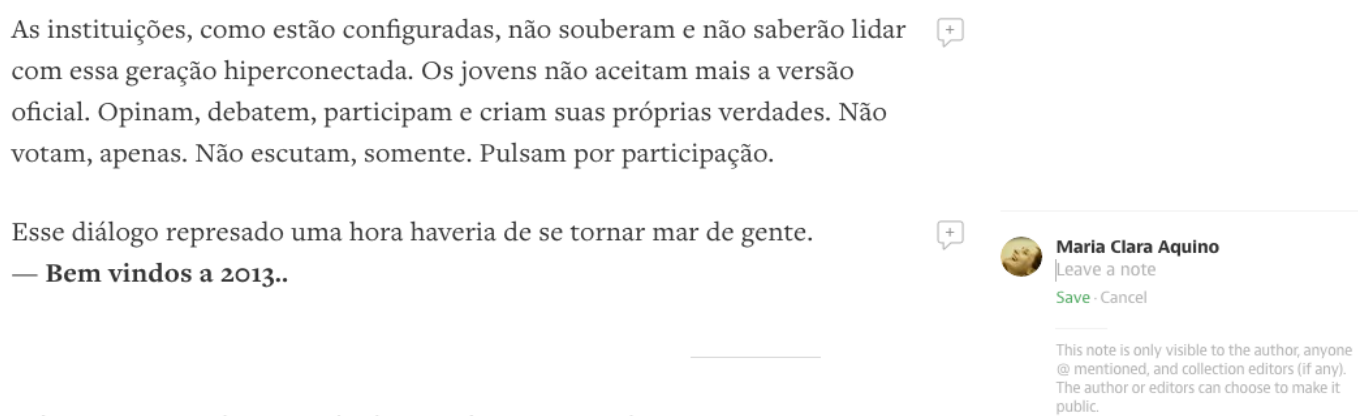

Figura 1

Exemplo da possibilidade de inserção de notas. Fonte: https://medium.com/@MidiaNINJA/ninja-2013f6d5618375b2 Acesso: 01/12/2016

Por estas notas (figura 1), que podem ou não ser públicas e permitem que os leitores mencionem uns aos outros, os produtores e consumidores dos conteúdos podem interagir de forma dialógica e estender o conteúdo indicando links para outras páginas e arquivos. No caso do Mídia Ninja, essa possibilidade existe, mas é pouco explorada, indo de encontro à 
PROGRAMA DE PÓS-GRADUAÇÃO EM COMUNICAÇÃO DA UNIVERSIDADE FEDERAL DE SANTA MARIA

preceitos ativistas pautados pelo diálogo e pela discussão dos temas. Praticamente não há a inserção de notas ao longo das publicações, seja por parte do coletivo, seja por parte dos leitores. Pode-se pensar que essa interatividade é transferida para outros espaços online quando há links para publicações no Facebook, por exemplo, como é o caso da primeira publicação feita no Medium pelo Mídia Ninja, que faz uma retrospectiva multimídia da atuação do coletivo em 2013, ou através das recomendações feitas pelos usuários entre si, prática que se aproxima da ideia de compartilhamento. No entanto, não há como atestar essa transferência. Há pedidos, feitos pelo próprio Mídia Ninja, de colaboração em termos de conteúdo, o que se poderia considerar como uma oportunidade de participação, entendendo-se aqui a participação como uma subcategoria da interatividade (AQUINO BITTENCOURT, 2012). No entanto, não há indicação alguma se essas colaborações são recebidas e publicadas na ferramenta.

Entende-se a interatividade estabelecida pelo Mídia Ninja através do Medium nos moldes do entendimento de Jenkins (2008), quando de sua diferenciação entre interatividade e participação. Trata-se de uma interatividade dos leitores com o conteúdo, com os links, ainda que limitada, na medida em que não adotam um caráter essencialmente participativo. Os leitores limitam-se a consumir e recomendar o conteúdo, deixando de lado a oportunidade de dialogarem $^{4}$ sobre os assuntos abordados dentro da própria ferramenta. Também não se identifica um incentivo do coletivo para tal prática, o que fortalece a constituição de uma narrativa unilateral, de exposição de dados e informações, sem qualquer conversação entre produtores e consumidores, ainda que haja possibilidade para tal.

\subsection{Multimidialidade}

Talvez seja a característica mais marcante na narrativa construída pelo Mídia Ninja no Medium. A primeira publicação apresenta uma retrospectiva da atuação do coletivo ao longo de 2013, mesclando diferentes formatos para narrar a cobertura de diferentes acontecimentos daquele ano. A maior parte das publicações feitas pelo coletivo no Medium são extensas não só em quantidade de texto, mas também de fotos e vídeos. A disponibilização de arquivos de áudio também é comum, ainda que menos frequente do que os outros formatos. A publicação

\footnotetext{
$4 \quad \mathrm{Na}$ publicação feita por Marília Moschkovich, em sua página no Medium, pode-se observar a apropriação dos usuários da possibilidade de interagir através das notas. Em quase todos os parágrafos do extenso texto publicado por Marília os leitores interagem entre si, e também com ela, através de notas. Disponível:https://medium.com/primavera-brasileira/esta-tudo-tao-estranho-e-nao-e-a-toa-dfa6bc73bd8a Acesso: 01/12/2016
} 
PROGRAMA DE PÓS-GRADUAÇÃO EM COMUNICAÇÃO DA UNIVERSIDADE FEDERAL DE SANTA MARIA

sobre o congresso do $\mathrm{MST}^{5}$ retrata claramente o esforço do coletivo em construir uma narrativa multimídia para expor a cobertura realizada nos cinco dias de congresso: há uma extensa exploração de textos e fotos, misturados a links externos, depoimentos e até um infográfico com dados sobre os números do congresso (figura 2).

\section{Congresso em números}

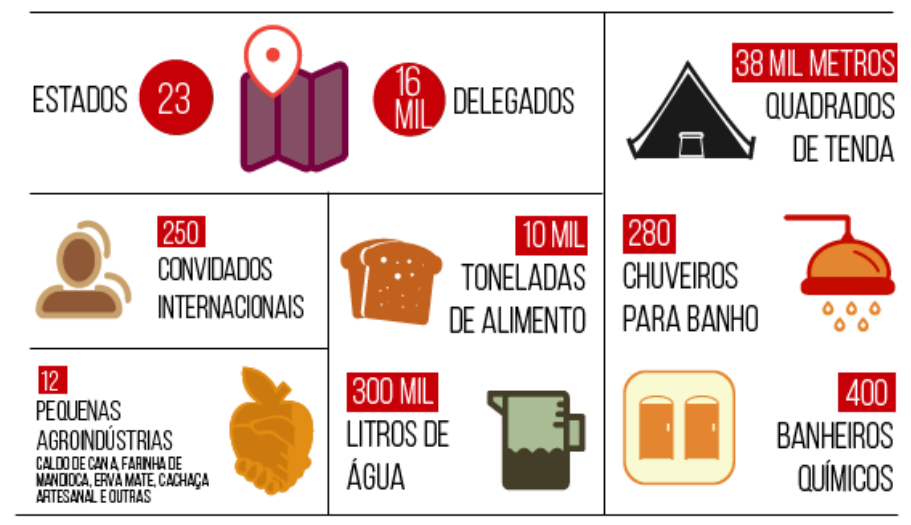

Hoje, o MST contabiliza 350 mil famílias assentadas em 8 milhões de hectares de 1200 municípios no país. São mais de 100 cooperativas e mais de

Figura 2: Exemplo do uso de diferentes formatos ao longo da publicação: https://medium.com/@ MidiaNINJA/a-trajetoria-e-as-lutas-do-mst-a02e6d9b64dd Acesso: 01/12/2016

Esse esforço multimídia pode indicar a importância que o coletivo dá ao MST e suas causas, convergindo com seus ideais de dar voz aos que pouco falam na mídia tradicional e assim cobrir pautas pouco exploradas pela imprensa de massa. Por outro lado, há também publicações do coletivo no Medium que não exploram essa diversidade de formatos, ficando apenas no texto, sem fotos, sem vídeos e sem links: apenas duas entre as 12 publicações observadas apresentam essa característica.

A multimidialidade presente nas publicações do coletivo no Medium extrapola a própria ferramenta, na medida em que agrega conteúdo de outros espaços online através dos links para posts no Facebook e conteúdos em outros sites, por exemplo, o que amplia a cobertura sobre o tema e oferece um complemento da narrativa que é construída a partir de fontes diversas - essa ampliação da multimidialidade conversa diretamente com a hipertextualidade. Essa multimidialidade também poderia ser explorada através da

\footnotetext{
${ }^{5}$ https://medium.com/@MidiaNINJA/a-trajetoria-e-as-lutas-do-mst-a02e6d9b64dd Acesso: 01/12/2016
} 
PROGRAMA DE PÓS-GRADUAÇÃO EM COMUNICAÇÃO DA UNIVERSIDADE FEDERAL DE SANTA MARIA

hipertextualidade, na medida em que produtores e leitores poderiam inserir links para conteúdos sob diferentes formatos através das notas - o que não ocorre, já que no caso do Mídia Ninja as notas praticamente não existem nas publicações.

\subsection{Hipertextualidade}

Também fortemente explorada ao longo das publicações do Mídia Ninja, ainda que o uso de hashtags, que também é aqui entendido como uma espécie de link (AQUINO BITTENCOURT, 2007), seja praticamente inexistente. O Medium não oferece a possibilidade de inserção de hashtags nas publicações, o que facilitaria a recuperação do conteúdo dentro da ferramenta. Poderiam, nesse caso, ser utilizadas e linkadas manualmente pelo Mídia Ninja, com resultados de buscas em sites de rede social, por exemplo, para conteúdos publicados sob as palavras-chave, agregando assim o material produzido pelo coletivo e disponibilizado em outros espaços online. Não há, no entanto, indício de uso de hashtags nas publicações do coletivo na ferramenta - quando há, elas não são linkadas para nenhuma outra página, arquivo ou documento (figura 3).

\section{A Mídia NINJA participou deste momento histórico. Veja agora o compilado de 5 dias intensos em Brasília (DF) registrados pela equipe NINJA e ainda os relatos de Oliver Kornblihtt, fotógrafo argentino que veio em missão acompanhar o congresso.}

\section{\#SomosTodosSemTerra}

Figura 3

Exemplo de uso de hashtag sem link. https://medium.com/@MidiaNINJA/a-trajetoria-e-as-lutas-do-msta02e6d9b64dd Acesso: 01/12/2016

Os links no Medium do Mídia Ninja aparecem ao longo dos textos, levando o leitor a muitos conteúdos publicados pelo próprio coletivo em outros espaços online, mas também para fontes externas. Quando Motta (2007) propõe o estudo da narrativa jornalística através do esforço de unir o que a dinâmica da atividade jornalística separa ao espalhar notícias isoladas sobre um determinado acontecimento, poderia-se assim pensar que o hipertexto, nesse caso, daria conta dessa tarefa de reunir no Medium conteúdos dispersos, produzidos pelo coletivo, sobre um mesmo tema. A hipertextualidade também poderia ser explorada nas notas, na medida em que tanto os administradores da página no Medium, quanto os leitores, poderiam ampliar a quantidade de conteúdo das publicações inserindo links nas notas. Tal 
PROGRAMA DE PÓS-GRADUAÇ̃̃O EM COMUNICAÇÃO DA UNIVERSIDADE FEDERAL DE SANTA MARIA

prática também não ocorre, no caso do Mídia Ninja, tendo em vista a ausência completa de notas nas publicações. Imagens não são linkadas e os vídeos podem ser abertos em suas plataformas originais de publicação, como o YouTube. Percebe-se limitações na atividade hipertextual diante das oportunidades que a inserção de links traria à narrativa do coletivo nessa ferramenta.

\title{
4.4. Personalização
}

Em qualquer página no Medium, o conteúdo é o mesmo para todos os leitores, ainda que a própria ferramenta permita uma personalização no sentido de que se pode assinar os perfis, ou seja, é o leitor que define, inicialmente, quem seguir e acompanhar as publicações. O esquema de recomendação permite que as pessoas indiquem publicações. Dessa forma, as publicações que uma pessoa recomenda chegam a todas as outras que a seguem no Medium. O indivíduo que segue o Mídia Ninja acompanha suas publicações e pode recomendá-las aos seus seguidores. Cada publicação mostra as pessoas que a recomendaram aos seus seguidores (figura 4).

\section{Recommends for "A Voz das Ruas Vive: Sobre a tragédia da morte de Santiago Andrade"}

\author{
C Gabriela Sarmet \\ briela Sarmet \\ Andreia Peroba Rosa \\ Fillipe Diniz \\ melhor que chico buarque
}

Follow

Follow

Figura 4: Exemplo de visualização de quem recomendou uma publicação:

https://medium.com/@MidiaNINJA/a-voz-das-ruas-vive-sobre-a-tragedia-da-morte-de-santiago-andrade6a779e00b7d4 Acesso: 01/12/16

Sobre o conteúdo especificamente, a personalização é livre por parte de quem gerencia a página, ou seja, as possibilidades de inserção de textos, imagens, fotos e áudios ao longo de cada publicação fica ao gosto de quem a produz, assim como a página do perfil, que também 
PROGRAMA DE PÓS-GRADUAÇÃO EM COMUNICAÇÃO DA UNIVERSIDADE FEDERAL DE SANTA MARIA

pode ser customizada, ainda que de forma limitada. Uma prática que caracteriza a personalização que o Mídia Ninja faz de seu conteúdo no Twitter, por exemplo, é o uso da hashtag \#midianinja, como uma espécie de assinatura do conteúdo. No Medium essa prática não ocorre, há pouco uso de hastags nas publicações, apenas a menção de créditos do coletivo em algumas das fotos e vídeos utilizados.

\subsection{Memória}

Ainda que com uma disposição cronológica das publicações, semelhante aos blogs, não há uma lista com os links de cada publicação para uma busca mais rápida, nem mesmo o uso de hashtags ao final de cada publicação, como acontece não só nos blogs, mas também em portais de notícias. A ferramenta disponibiliza uma caixa de buscas, que sugere a pesquisa por tópico ou tema, através da qual é possível recuperar conteúdo a partir de palavras-chave. Não há um esquema de busca avançada. É possível visualizar, abaixo disso, os perfis que o usuário segue (figura 5).

\section{Collections}

Stories grouped by theme or topic

Q ßearch

COLLECTIONS YOU FOLLOW

Figura 5: Exemplo de mecanismo de busca e armazenamento: https://medium.com/collections Acesso:

$01 / 12 / 2016$

O conteúdo disponibilizado tem potencialidade de ser enriquecido de forma colaborativa, através das notas que podem ser inseridas ao longo das publicações, mas como já foi dito, essa prática não foi incorporada pelos leitores do Mídia Ninja. Não há um esforço expressivo de organização o conteúdo, ainda que se perceba a intenção do coletivo em agrupar o conteúdo sobre um tema numa única ferramenta, utilizando para isso diferentes formatos de visualização. Nesse caso, a multimidialidade prevalece sobre a hipertextualidade, por isso a organização do conteúdo é prejudicada. É o leitor que, caso queira recuperar alguma publicação do coletivo, precisa encontrar em meio a tudo o que já foi publicado pelo coletivo aquilo que busca, mas conta com pouco auxílio para isso. 


\subsection{Instantaneidade}

Diferente dos sites de notícias que baseiam suas publicações na atualização contínua, com seções "últimas notícias" ou "minuto a minuto", na tentativa de cobrir os fatos à medida em que acontecem, ou de perfis no Twitter que exploram a instantaneidade promovendo coberturas ao vivo, o Medium do Mídia Ninja não apresenta essa característica. Trata-se de um espaço que pode ser comparado com os especiais dos portais de notícia ou com reportagens mais extensas que se dedicam a abordar um tema ou acontecimento e assim esgotam o assunto através de um trabalho mais longo de apuração e edição, reunindo um maior número de dados, fontes, formatos e informações depois que eles acontecem, numa espécie de análise e observação mais cuidadosa. Não há indícios claros de edição posterior das publicações com a inserção de mais conteúdo. Também não há periodicidade regular nas publicações, de forma que desde a primeira, que ocorreu em janeiro de 2013, apenas 12 publicações foram feitas (mais as que foram traduzidas para o espanhol e para o inglês), até 30 de outubro, sendo que a última aconteceu em 27 de maio de 2014.

\section{DISCUSSÃO}

“...tornar a atualidade mais do que um momento que logo em seguida se perderá da memória", como diz Carvalho sobre a narrativa que deriva da noção de atualização, parece ser um dos propósitos do Mídia Ninja ao utilizar o Medium para a construção de narrativas sobre os acontecimentos. A prioridade do coletivo nessa ferramenta não é cobrir os fatos no momento em que acontecem, nem mesmo provocar o debate sobre os temas abordados ou os protestos relatados, como se poderia imaginar possível através das notas. O que prepondera no uso da ferramenta é reunir o resultado da atuação do coletivo em diferentes espaços online, criando um repositório de conteúdo sobre os temas abordados, sem pressa de disponibilizar a compilação dos materiais, seguindo o ritmo dos acontecimentos. O conteúdo disponível nos sites de redes sociais é, inclusive, aproveitado no Medium, servindo como referência multimídia das coberturas que o Mídia Ninja realiza. Trata-se, nesse sentido, de um espaço onde o conteúdo pode ser apurado e trabalhado sem a pressão da instantaneidade característica das coberturas ao vivo realizadas pelo coletivo no Twitter, por exemplo.

Tomando o Medium como referência, pode-se inferir que o Mídia Ninja pouco se apropria e provoca transformações nas características de jornalismo digital elencadas, na 
PROGRAMA DE PÓS-GRADUAÇÃO EM COMUNICAÇÃO DA UNIVERSIDADE FEDERAL DE SANTA MARIA

medida em que pouco as explora nessa ferramenta. Trata-se aqui da limitação deste artigo, que se volta apenas para uma ferramenta utilizada pelo coletivo. Surgem então questionamentos sobre se essa exploração também é escassa em espaços como Facebook e Twitter, usados com frequência pelo Mídia Ninja. Se nesses sites de redes sociais a interatividade, por exemplo, é incentivada e explorada a partir dos comentários e dos compartilhamentos que potencializam a visibilidade dos conteúdos, no Medium esse tipo de atividade é baixo, diante da quase completa ausência de notas e poucas recomendações feitas por outros usuários. Enquanto uma publicação na fanpage do coletivo pode chegar a ter 398

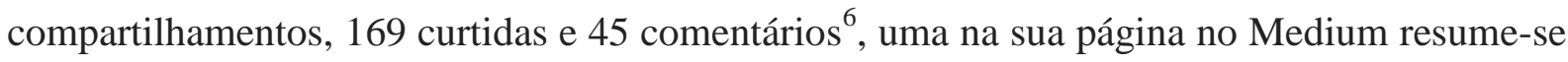
a seis recomendações, sem nenhuma nota adicionada ${ }^{7}$. A quem atribuir a responsabilidade por esse baixo nível de interatividade? Fatores como a falta de estímulo por parte do Mídia Ninja, bem como ao pouco número de seguidores do coletivo nesse espaço podem indicar essa apropriação mais tímida, de ambas as partes, o que abre espaço para a ampliação da investigação sobre a interatividade e demais características.

No caso do Mídia Ninja, o uso do Medium acaba não tendo relevância nas ações midiativistas do coletivo. Da forma como Castells (2012) aponta apropriações tecnológicas em contexto de movimentos em rede, a maneira como o Mídia Ninja pouco atualiza sua página no Medium e pouco explora algumas de suas funcionalidades reflete a irrelevância que ela assume dentro das práticas ativistas do grupo que se propõe a narrar os fatos a partir das ruas, no momento em que acontecem. Não se trata, porém, de ignorar o valor da ferramenta como um repositório de conteúdo onde os dados podem ser trabalhados de forma mais detalhada e aprofundada. Há que se considerar também a recente adoção do Medium no conjunto de ferramentas do coletivo, de modo que pode-se esperar novas apropriações ao longo do tempo.

É incontestável, ainda assim, que as publicações ali disponibilizadas têm alcançado pouca visibilidade, pois não mobilizam o suficiente, como aborda Assis (2006), para caracterizar o uso da ferramenta como mais um instrumento ativista. Isso porque o pouco uso e o pouco aproveitamento de algumas das características aqui analisadas não chegam a viabilizar interações (BRAGA, 2012b). As tentativas de uso da ferramenta servem como registro da memória dos fatos, ainda que essa memória não seja efetivamente organizada de

\footnotetext{
6 https://www.facebook.com/video.php?v=399355016889316 Acesso: 06/11/14

7 https://medium.com/@ MidiaNINJA/a-trajetoria-e-as-lutas-do-mst-a02e6d9b64dd Acesso: 06/11/14
}

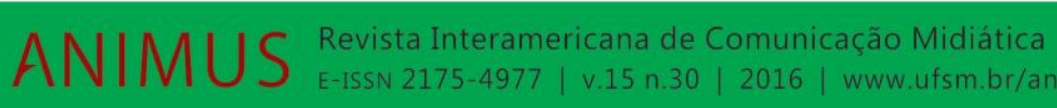


PROGRAMA DE PÓS-GRADUAÇÃO EM COMUNICAÇÃO DA UNIVERSIDADE FEDERAL DE SANTA MARIA

modo a ampliar, através da interatividade e da hipertextualidade, a circulação das publicações ali feitas.

Pensando a apropriação que o Mídia Ninja faz do Medium na sua rotina de cobertura e de construção de narrativa sobre as ruas, a contribuição para a narrativa jornalística digital é mais produtiva no que se refere à questões de memória e aprofundamento dos temas abordados, incorporando nessa narrativa a hipertextualidade, a multimidialidade e a memória como prioridades sobre interatividade, instantaneidade e personalização. Essa apropriação serve como exemplo para pensar a configuração de abordagens mais longas em ambientes diversos de sites de notícias onde a exigência da instantaneidade acaba gerando matérias mais curtas e em maior quantidade, em contraposição à espaços que priorizam o detalhe e a multiplicidade de formatos para narrar um acontecimento. A análise mostra que nem sempre uma nova ferramenta é sinônimo de evolução em termos de uso, pois a apropriação acaba definindo as formas pelas quais essas características são incorporadas nas coberturas. Esse caso demonstra como potencialidades subutilizadas deixam de contribuir para que a narrativa digital acompanhe a evolução do meio e também como a midiatização do ativismo nem sempre significa que as apropriações estimulem o amadurecimento das práticas comunicacionais.

\section{CONSIDERAÇÕES}

A construção de tentativas comunicacionais interativas é guiada, em grande parte, pelo esforço de gerar novos canais de comunicação, alternativos à mídia tradicional e, ao mesmo tempo, com potencial de gerar a visibilidade que os grandes veículos são capazes de conferir aos conteúdos que publicam. Ideias democráticos também orientam essas tentativas, que encontram nas redes digitais espaços que combinam a liberdade de emissão com a pluralidade de formatos através dos quais um conteúdo pode ser mostrado. Inerentes ao ambiente digital, as características aqui trabalhadas são frequentemente apropriadas e reapropriadas na construção e no desenvolvimento dessas tentativas, como é o caso da apropriação do Medium feita pelo Mídia Ninja.

Para o jornalismo praticado pela imprensa tradicional, dita oficial, a proliferação dessas tentativas por movimentos sociais e coletivos midiáticos independentes enriquece a discussão sobre a narrativa jornalística digital a partir das apropriações de diferentes ferramentas e dispositivos por ativistas, cidadãos e jornalistas independentes. Essas 
PROGRAMA DE PÓS-GRADUAÇÃO EM COMUNICAÇÃO DA UNIVERSIDADE FEDERAL DE SANTA MARIA

apropriações estimulam a reflexão de diferentes aspectos das práticas jornalísticas e o impacto de características que são trabalhadas de diferentes formas em espaços diversos da rede, e foi isso que este artigo buscou realizar a partir do tensionamento das características do jornalismo digital numa apropriação feita pelo Mídia Ninja de uma ferramenta de publicação de conteúdo.

O enquadramento dessa análise a partir de uma premissa de midiatização do ativismo demonstra o quanto o potencial de visibilidade que as redes podem agregar aos esforços midiáticos independentes retrata o atravessamento dos campos social e midiático, ao mesmo tempo em que desamarra laços de dependência entre ativistas e mídia tradicional. Ao mesmo tempo, algumas formas pelas quais tentativas comunicacionais interativas, e pretensamente colaborativas, ainda se prendem à modelos e lógicas unidirecionais e verticais revelam a imaturidade de apropriações que, mesmo guiadas pela democratização da voz e do acesso à informação, pouco interferem-no desenvolvimento da narrativa jornalística digital. Esforços nesse sentido de transformação e evolução das práticas são estimulantes vindos seja da mídia tradicional ou independente, o fato é que muitas vezes esta acaba rendendo-se à hábitos e costumes daquela, impedindo o amadurecimento de ambas.

\section{REFERÊNCIAS}

AQUINO BITTENCOURT, M.C. Hipertexto 2.0, folksonomia e memória coletiva: Um estudo das tags na web. E-Compós (Brasília), v. 9, p. 1-15, 2007.

AQUINO BITTENCOURT, M.C. Convergência midiática entre televisão e web: proposta de categorização analítica. Tese de Doutorado. Programa de Pós-Graduação em

Comunicação e Informação. Universidade Federal do Rio Grande do Sul, 2012.

ASSIS, E. G. Táticas lúdico-midiáticas no ativismo político contemporâneo. Dissertação de mestrado. Programa de Pós-Graduação em Ciências da Comunicação da Universidade do Vale do Rio dos Sinos. 2006.

BERTOCCHI, D. A narrativa jornalística no ciberespaço: transformações, conceitos e questões. Dissertação de mestrado. Universidade do Minho, Portugal. 2006.

BOURDIEU, P. Questões de sociologia: algumas propriedades dos campos. Rio de Janeiro: Marco Zero, 1983.

BRAGA, José Luiz. Circuitos versus campos sociais. In: MATTOS, MA.; JANOTTI JUNIOR, J.; JACKS, N. Mediação e midiatização. Livro Compós 2012. Salvador, Brasília. EDUFBA, 2012a. 
PROGRAMA DE PÓS-GRADUAÇÃO EM COMUNICAÇÃO DA UNIVERSIDADE FEDERAL DE SANTA MARIA

BRAGA, José Luiz. Uma teoria tentativa. In: Revista da Associação Nacional dos Programas de Pós-Graduação em Comunicação. E-Compós, Brasília, v. 15, n. 3, set./dez., 2012b.

CANAVILHAS, João Messias. Webjornalismo: considerações gerais sobre jornalismo na web. In: Biblioteca Online de Ciências da Comunicação. 2001. Disponível:

http://www.bocc.ubi.pt/pag/canavilhas-joao-webjornal.pdf Acesso: 30/10/14.

CANAVILHAS, João; SANTANA, Douglas Cavallari. Jornalismo para plataformas móveis de 2008 a 2011: da autonomia à emancipação. In: Líbero - São Paulo - v. 14, n. 28, p. 53-66, dez. De 2011.

CARVALHO, C.A. Entendendo as narrativas jornalísticas a partir da tríplice mimese proposta por Paul Ricoeur. In: Revista Matrizes Ano 6 - No 1 jul./dez. 2012 - São Paulo, p. 169-187.

CASTELLS, M. O poder da comunicação. Editora Gulbenkian. 2009.

CASTELLS, M. Networks of outrage and hope: social movements in the internet age. Politik. Wiley, 2012.

FAUSTO NETO, A. Fragmentos de uma analítica da midiatização. In: Revista Matrizes. n. 2/abril 2008. Disponível: http://www.matrizes.usp.br/index.php/matrizes/article/view/88 Acesso: 30/10/14

FAUSTO NETO, Antônio. A circulação além das bordas. In: FAUSTO NETO, Antônio; VALDETTARO, Sandra (ORGs.) Mediatización, Sociedad y Sentido: diáologos entre Brasil y Argentina. Programa de Cooperación Científico Tecnológico MINCYT-CAPES 2009-2010.

GILMOR, Dan. We the Media: Grassroots Journalism By the People, For the People. Sebastopol: O’Reilly Media. Disponível em http://www.authorama.com/we-the-media1.html Acesso: 30/10/14

GOHN, MGM. Movimentos sociais e redes de mobilização civis no Brasil contemporâneo. Ed. Vozes: Petrópolis, 2010.

JENKINS, Henry. Cultura da Convergência. Editora Aleph: São Paulo, 2008.

LINDEMANN, C. Jornalismo participativo na Internet: novo suporte, novas práticas, novos conceitos. Animus (Santa Maria), v. V, p. 149-167, 2006.

MACHADO, E.; PALACIOS, M. Um modelo híbrido de pesquisa: a metodologia aplicada pelo GJOL. In: LAGO, C.; BENETTI, M. (ORGs.). Metodologia de Pesquisa em Jornalismo. Petrópolis, RJ: Vozes, 2007.

MALINI, F. Modelos de colaboração nos meios sociais da internet: uma análise a partir dos portais de jornalismo participativo. Trabalho apresentado no NP Tecnologias da Informação e da Comunicação- Encontro dos Núcleos de Pesquisa em Comunicação, evento componente do XXXI Congresso Brasileiro de Ciências da 
Comunicação. 2008. Disponível:

http://portcom.intercom.org.br/navegacaoDetalhe.phpid=35526 Acesso: 30/1014

MIELNICZUK, L. Dez anos de jornalismo online: muitas indagações e poucas respostas. In: Anais do III Congresso Nacional de Pesquisadores em Jornalismo (SBPJor), 2005, Florianópolis.

MIELNICZUK, L. Jornalismo na web: uma contribuição para o estudo do formato da notícia na escrita hipertextual. Tese de doutorado. Universidade Federal da Bahia. Faculdade de Comunicação. Salvador, 2003. Disponível: http://poscom.tempsite.ws/wpcontent/uploads/2011/05/Luciana-Mielniczuk.pdf Acesso: 04/11/14

MOTTA, L. G. Análise pragmática da narrativa jornalística. In: LAGO, C.; BENETTI, M. (ORGs.) Metodologia de Pesquisa em Jornalismo. Petrópolis, RJ: Vozes, 2007.

MOTTA, L. G. Retorno da narrativa: a busca do significado. In: Signo. Santa Cruz do Sul, v. 37 n.62, p. 53-64, jan.-jun., 2012

PALACIOS, Marcos; MIELNICZUK, L.; BARBOSA, Suzana ; RIBAS, Beatriz ;NARITA, $\mathrm{S}$. Um Mapeamento de características e tendências no jornalismo online brasileiro e português. Comunicarte, Aveiro- Portugal, v. 1, n. 2, 2002. Disponível:

http://www.facom.ufba.br/jol/pdf/2002_palacios_mapeamentojol.pdf Acesso: 04/11/14

SCHWINGEL, Carla. Jornalismo digital de quarta geração: a emergência de sistemas automatizados para o processo de produção industrial no Jornalismo Digital. Disponível: http://www.ufrgs.br/gtjornalismocompos/doc2005/carlaschwingel2005.doc Acesso: 04/11/14.

SILVA, Fernando Firmino. Jornalismo live streaming: tempo real, mobilidade e espaço urbano. In: Encontro Nacional de Pesquisadores em Jornalismo - SBPJOR, 2008, São Bernardo do Campo - SP. Encontro Nacional de Pesquisadores em Jornalismo - SBPJOR, 2008. Disponível:

http://sbpjor.kamotini.kinghost.net/sbpjor/admjor/arquivos/individual40fernandofirmino.pdf Acesso: 06/11/14

TRÄSEL, Marcelo ; PRIMO, Alex F T . Webjornalismo participativo e a produção aberta de notícias. Contracampo (UFF), Rio de Janeiro, v. 14, p. 36-46, 2006.

VERÓN, Eliseo. Teoria da midiatização: uma perspectiva semioantropológica e algumas de suas consequências. In: Revista Matrizes, v. 8, n. 1, jan/jun. 2014, São Paulo.

Original recebido em: 19-11-2014

Aceito para publicação em: 18-08-2016

Maria Clara Aquino Bittencourt

Doutora e mestre em Comunicação e Informação pelo Programa de Pós-Graduação em Comunicação e Informação da Universidade Federal do Rio Grande do Sul. Graduada em Comunicação Social, habilitação Jornalismo, pela Universidade Católica de Pelotas. Atua na área de Cibercultura, com ênfase no campo acadêmico, principalmente nos seguintes temas: 
PROGRAMA DE PÓS-GRADUAÇÃO EM COMUNICAÇÃO DA UNIVERSIDADE FEDERAL DE SANTA MARIA

convergência midiática, espalhamento de informações, movimentos e mobilizações sociais em rede, hipertexto e jornalismo digital. Atualmente é bolsista CAPES de estágio pós-doutoral do Programa de Pós-Graduação em Ciências da Comunicação da Universidade do Vale do Rio dos Sinos (UNISINOS) e membro do Grupo de Pesquisa Laboratório de Investigação do Ciberacontecimento, na mesma instituição.

Esta obra está licenciada sob uma Licença Creative Commons. 